\title{
Excess Mortality due to natural causes among whites and blacks during the COVID-19 pandemic in Brazil
}

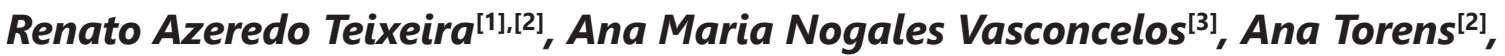 \\ Elisabeth Barboza França ${ }^{[1]}$, Lenice Ishitani ${ }^{[4]}$, Ana Luiza Bierrenbach ${ }^{[5]}$, \\ Daisy Maria Xavier de Abreu ${ }^{[4]}$ and Fátima Marinho ${ }^{[2]}$
}

[1]. Universidade Federal de Minas Gerais, Faculdade de Medicina, Programa de Pós-Graduação em Saúde Pública, Belo Horizonte, MG, Brasil.

[2]. Vital Strategies, New York, United States of America.

[3]. Universidade de Brasília, Departamento de Estatística, Brasília, DF, Brasil.

[4]. Universidade Federal de Minas Gerais, Grupo de Pesquisas em Epidemiologia e Avaliação em Saúde, Belo Horizonte, MG, Brasil.

[5]. Hospital Sírio-Libanês, Instituto de Ensino e Pesquisa, São Paulo, SP, Brasil.

\begin{abstract}
Introduction: Excess Mortality by all causes considers deaths directly related to COVID-19 and those attributed to conditions caused by the pandemic. When stratified by social dimensions, such as race/color, it allows for the evaluation of more vulnerable populations. The study estimated the excess mortality by natural causes, separating the white and black populations in 2020. Methods: Public civil registration data on deaths observed in 2020, corrected for under registration, were used. The expected number of deaths was estimated based on the mortality rates observed in 2019, applied to the estimated population in 2020. The difference between the values expected and observed and the proportion of excess was considered the excess mortality. Results: The present study found an excess of 270,321 deaths (22.2\% above the expected) in 2020. Every state of Brazil reported deaths above the corresponding expected figure. The excess was higher for men $(25.2 \%)$ than for women (19.0\%). Blacks showed an excess of $27.8 \%$, as compared to whites at $17.6 \%$. In both sexes and all age groups, excess was higher in the black population, especially in the South, Southeast, and Midwest regions. São Paulo, the largest in population number, had twice as much excess death in the black population (25.1\%) than in the white population (11.5\%). Conclusions: The present study showed racial disparities in excess mortality during the COVID-19 pandemic in Brazil. The higher excess found for the black suggests an intrinsic relationship with the socioeconomic situation, further exposing the Brazilian reality, in which social and structural inequality is evident.
\end{abstract}

Keywords: Excess mortality. COVID-19. Race. Skin color. Health information system.

\section{INTRODUCTION}

The coronavirus disease 2019 (COVID-19) pandemic, declared an internationally important public health emergency in January 2020 by the World Health Organization (WHO) ${ }^{1}$ and a national important public health emergency by the Brazilian Ministry of Health $^{2}$ in February 2020, caused more than 7.6 million cases and approximately 195,000 notified deaths in $2020^{3}$ in Brazil. These numbers are expressive and place Brazil as the second country in terms of number of cases and deaths, behind only the United States ${ }^{4}$.

\footnotetext{
Corresponding author: Renato Azeredo Teixeira.

e-mail: renato115@yahoo.com

(D) https://orcid.org/0000-0002-1259-6812

Received 5 May 2021

Accepted 9 August 2021
}

Confirmation of COVID-19 as the cause of death in Brazil depends mostly on positive result in the exam for the detection of the genetic material of SARS-CoV-2 (RT-PCR - polymerase chain reaction). In the early months of the pandemic, given the low testing capacity almost everywhere, the Brazilian government prioritized the testing of hospitalized patients with a suspicion of COVID-19 and, in some states, instituted sample collection after death for this specific exam 5 . In addition to the low testing capacity, other problems, such as difficulty in collecting, storing, and transporting samples in a timely manner, indicate the existence of underreporting of cases and deaths in the country. Therefore, the real number of underlying causes of the deaths can hardly be obtained by using crude mortality data from local health information systems ${ }^{6}$.

Estimating COVID-19 specific mortality is not a Brazilian exclusive problem ${ }^{7}$. Difficulties in accurately establishing the 
underlying cause of death make mortality by all causes an important indicator of the magnitude of the impact of the epidemic in the population mortality. This occurs because, apart from the disease causing an elevated number of direct deaths per se, it also affects the number of indirect deaths due to other causes, as a consequence of the overburdening of the health system, population fear of seeking out medical care for sudden illnesses, as well as chronic conditions due to the risk of SARS-CoV-2 infection being high in hospitals and ambulatory facilities, restrictions on people's circulations, among other problems ${ }^{8}$. Hence, since all-cause mortality is a simple indicator that depends solely on the count of the total number of deaths, which is a type of data potentially faster to obtain, it becomes an essential indicator to aid in decision-making and the design of actions to control epidemics. This indicator can be extremely useful in a context of social and economic inequalities, where the poorest population and those living in difficult to reach regions have very low access to quality health care, with a subsequent impact on the profile of their causes of death 9 . In a crisis scenario such is the current one with the COVID-19 pandemic, the uneven access to diagnoses and to quality care for the sick and dying are likely reflected in an uneven mortality risk. In this sense, information stratified by social dimensions, such as race/color, becomes important in the evaluation of the differential impact of COVID-19 on more vulnerable populations ${ }^{10}$. The objective of the present study is to estimate excess mortality by natural causes in the white and black populations, according to age and sex, in Brazil and its states in 2020.

\section{METHODS}

\section{Data sources}

This observational study used, as one of its data sources, the Mortality Information System (SIM, in Portuguese) of the Brazilian Ministry of Health, which is responsible for collecting, storing, and distributing information on deaths in the Brazilian territory. The SIM is the main source of data about deaths in the country and follows a standardized process from data collection to several data quality checks leading to the selection of the underlying cause of death ${ }^{11-12}$. However, the SIM has a delay of approximately two years until it finally publishes the official data. Given the unavailability of the official SIM data for 2020, our study had to use the data from the Civil Registry (CR) for this year, made available by the Association of Natural Persons Registers (ARPEN-Brazil), through the Transparency Website ${ }^{13}$. The CR data, from ARPEN website, provides data on mortality by natural causes in Brazil since 2019 .

Although the SIM and the CR databases are distinct, the Death Certificate (DC) is the common collection instrument of both systems. In Brazil, the DC is usually filled out by the attending physician and, less commonly, by coroners and pathologist. After completion, three copies of the DC are sent out: the first goes to the data processing section of the SIM, usually the municipal Health Secretariat; the second to the family of the deceased so that it can be officially recorded and filed at the notary public office, which is a requirement for burial and other bureaucratic needs; and the third copy should remain at the notifying institution (hospital, other health establishment, coroner's office, or SVO) to be included in the medical records of the deceased. This procedure may vary according to whether the death was due to natural or external causes ${ }^{14}$.
In this study we used both the SIM and the ARPEN data. The SIM had to be used so as to correct for under-reporting as explained below. It is important to emphasize that the data from ARPEN used in this work refer to deaths by natural causes, identified as such in the section "type of death" (natural or external cause). For compatibility purposes, DCs issued by the coroner's office were excluded from the SIM, so that the definitions of death from natural causes were as compatible as possible in the two databases.

\section{Correction of under-reporting in the CR}

Given that the registered deaths are inferior in number in the $\mathrm{CR}$ data as compared to the SIM in most states of Brazil ${ }^{15}$, we used a correction factor to account for the numeric differences of the two sources in 2020, according to the numbers observed in both sources in 2019, separately for each federal unit, sex, and age. For example, if 100 deaths and 120 deaths were respectively registered in CR and SIM in 2019 for males over 80 years of age in the state of Rio de Janeiro, the correction factor used in 2020 for this stratum was 1.2. Only after this correction was it possible to compare the CR data for 2020 with the expected deaths data for this year. For the state of São Paulo, the opposite situation was observed in 2019, that is, the SIM had higher numbers than the CR. For this reason, the correction made for this state had to be different from the others, having applied a correction factor of less than 1 , so that the data from both databases were comparable.

As regards the variable race/color, over $17 \%$ of records of the CR data have missing values. Meanwhile, in the SIM data, less than 3\% have missing values on recent years. To avoid discarding CR observations with missing values on race/color, a proportional redistribution was performed, based on the proportion of deaths by race/color from the SIM, according to sex, age, and federal unit.

\section{Level of Analysis}

In order to show the local realities, this study considered information according to sex, age and race/color in the 27 federal units (26 states plus the federal district), for each epidemiological week (EW), according to the date of death. The following age groups were used: 0 to 29, 30 to 59, 60 to 79, and 80 years of age and older. As race/color categories, "white" and "black" (represented by the sum of blacks and browns, called 'pardos' in Portuguese) were used, which represent $99 \%$ of all deaths with information on race/color.

\section{Excess mortality}

The indicator "excess mortality" took into consideration the difference between the observed values and the expected values at the most disaggregated level, in other words, according to sex, age group, race/color, EW, and state. The more aggregated final estimates were obtained from the sum of those more disaggregated levels. The "expected deaths" were estimated using the mortality rates observed in 2019 and applied to the 2020 population. For example, in 2019, 77 deaths were observed in epidemiological week 20 among 30- to 59-year-old white females in Minas Gerais, which results in a rate of 4.2 deaths per 100,000 inhabitants (population of $1,811,637)$. Applying this rate in the population of 2020 , we 
expected 78 deaths for this year (population of 1,827,084 inhabitants in 2020). The population data estimated by race/color was obtained using the proportions observed in the microdata of the National Household Sample Survey (PNAD) ${ }^{16}$. The PNAD is a periodic structural survey conducted by the Brazilian Institute of Geography and Statistics (IBGE), which aims to monitor the evolution of the workforce and other information necessary for the study of the country's socioeconomic development, by social analysts and public policymakers. The microdata was applied to the population projections by the IBGE - the official intercensal population estimates ${ }^{17}$. The "observed deaths" refer to the CR data for 2020, to which we applied the correction factors mentioned above. The positive difference between the observed values and the expected values by EW, for 2020, were considered as "excess deaths". The excess mortality proportion was calculated as the ratio of the excess and the expected values, multiplied by 100 . A sensitive analysis using Poisson regression is presented in the Supplementary Material Tables 1-4.

\section{RESULTS}

In Brazil, from EW 12 (March 15 $\left.{ }^{\text {th }}, 2020\right)$ on, there is a sustained excess of deaths, intensified dramatically from EW 17 (April 19th) on. This excess reached its peak between May 3rd and $16^{\text {th }}$, with over 32,000 deaths for both whites and for blacks, including over 17,000 blacks and over 15,000 whites (Figure 1).

Table 1 shows the number of excess deaths in the country, its regions, and its states, according to race/color. For 2020, 1,216,296 deaths by natural causes were expected in the country. This number represents a $22 \%$ increase from the amount expected for the year, which means an excess of 270,321 deaths. When analyzed by race/color, blacks showed higher values in comparison to the white population, with $27.8 \%(n=153,284)$ deaths above the expected number, while whites reached $17.6 \%(n=117,037)$ above the expected figure.

Every state reported an excess of deaths above the expected figure for 2020, ranging from $10.2 \%$ in Rio Grande do Sul to $62.7 \%$ in Rondônia. The Southeast, Northeast, and North regions were the most affected. In 2020, there were 108,218 (19.3\% excess) deaths above the expected figure; in the Northeast, the number was 82,463 deaths, $26.4 \%$ excess deaths; and in the North region, there were 29,043 deaths, corresponding to $39.9 \%$ excess deaths, the highest among the Brazilian regions.

There was a higher excess mortality for blacks with higher differences in proportions among the population groups of the Southeast (26.1\% among blacks and $15.5 \%$ among whites), and South (22.8\% among blacks and $11.9 \%$ among whites). In the North region, excess mortality was higher among the white population: $37.8 \%(n=21,558)$ and $47.5 \%(n=7,515)$ of excess deaths among the black and white populations, respectively. In the Northeast region, the proportion of excess was similar for the two groups, reaching $26.5 \%$ for whites and $26.4 \%$ for blacks.

Among the states, São Paulo stands out for showing not only the highest absolute numbers of excess deaths, but also for having

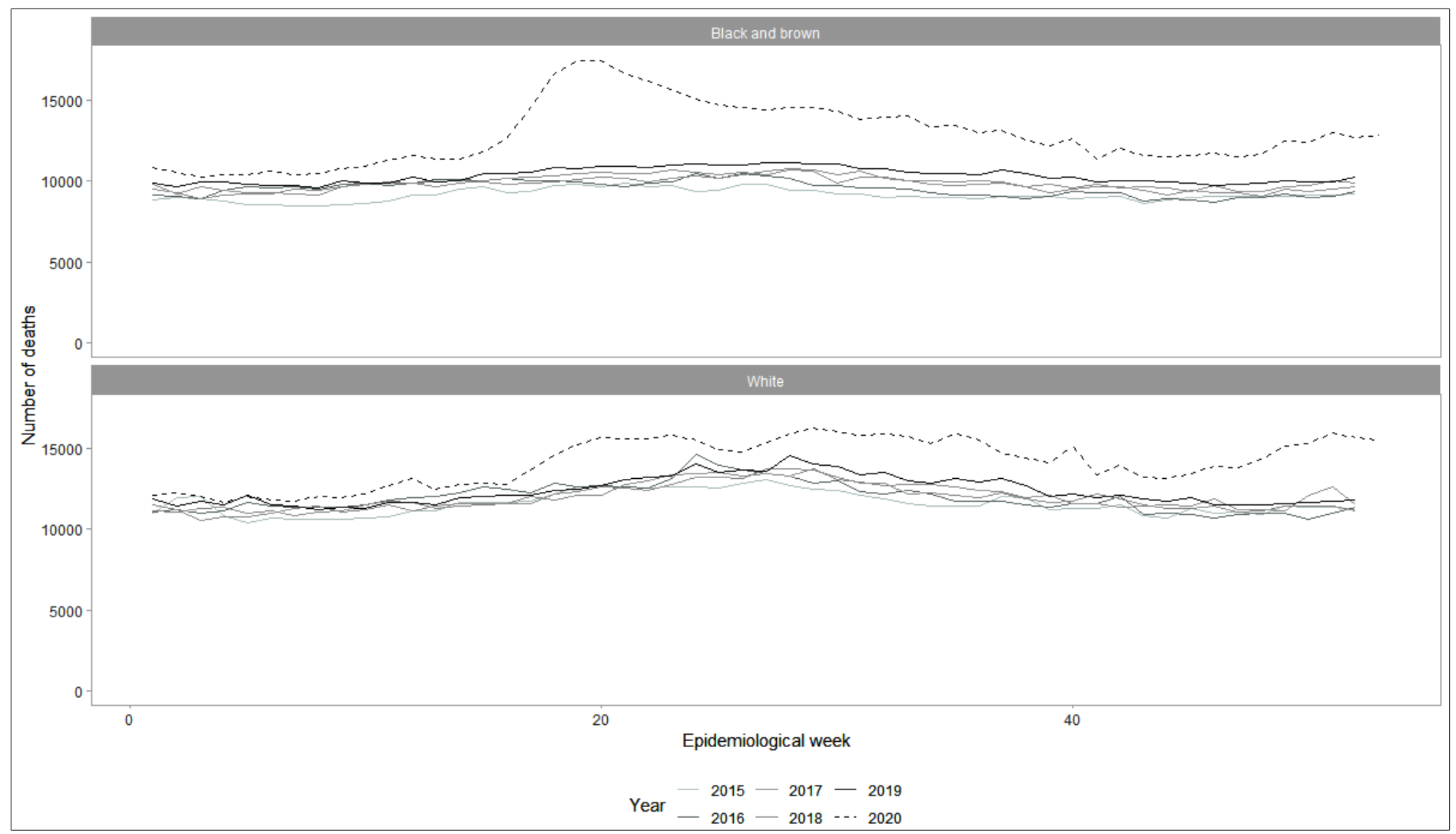

FIGURE 1: Number of observed deaths per week according to race/color. Brazil, 2015 to 2020. Data sources: SIM between 2015 and 2019 and CR (ARPEN) in 2020. 
TABLE 1: Number of deaths expected and in excess, and proportion of excess mortality, according to race/color. Brazil, regions, and states, 2020.

\begin{tabular}{|c|c|c|c|c|c|c|c|c|c|}
\hline \multirow{2}{*}{ Location } & \multicolumn{3}{|c|}{ White } & \multicolumn{3}{|c|}{ Black } & \multicolumn{3}{|c|}{ White+Black } \\
\hline & Expected & Excess & $\%$ & Expected & Excess & $\%$ & Expected & Excess & $\%$ \\
\hline Midwest & 35,794 & 10,847 & 30.3 & 42,139 & 14,125 & 33.5 & 77,932 & 24,972 & 32.0 \\
\hline Federal District & 6,725 & 2,136 & 31.8 & 6,858 & 2,836 & 41.4 & 13,583 & 4,972 & 36.6 \\
\hline Goiás & 15,798 & 4,418 & 28.0 & 18,510 & 5,501 & 29.7 & 34,307 & 9,918 & 28.9 \\
\hline Mato Grosso do Sul & 7,251 & 1,974 & 27.2 & 7,269 & 2,206 & 30.3 & 14,520 & 4,180 & 28.8 \\
\hline Mato Grosso & 6,020 & 2,319 & 38.5 & 9,502 & 3,583 & 37.7 & 15,522 & 5,901 & 38.0 \\
\hline North & 15,834 & 7,515 & 47.5 & 57,036 & 21,558 & 37.8 & 72,870 & 29,073 & 39.9 \\
\hline Acre & 720 & 535 & 74.3 & 2,860 & 828 & 29.0 & 3,580 & 1,363 & 38.1 \\
\hline Amazonas & 2,770 & 1,569 & 56.7 & 12,320 & 5,782 & 46.9 & 15,090 & 7,351 & 48.7 \\
\hline Amapá & 712 & 407 & 57.2 & 2,247 & 1,092 & 48.6 & 2,959 & 1,500 & 50.7 \\
\hline Pará & 6,624 & 2,956 & 44.6 & 28,792 & 9,792 & 34.0 & 35,416 & 12,748 & 36.0 \\
\hline Roraima & 2,752 & 973 & 35.4 & 4,435 & 1,601 & 36.1 & 7,187 & 2,574 & 35.8 \\
\hline Rondônia & 425 & 283 & 66.7 & 1,515 & 933 & 61.6 & 1,940 & 1,217 & 62.7 \\
\hline Tocantins & 1,832 & 791 & 43.2 & 4,867 & 1,529 & 31.4 & 6,700 & 2,320 & 34.6 \\
\hline Northeast & 87,272 & 23,157 & 26.5 & 225,487 & 59,306 & 26.3 & 312,760 & 82,463 & 26.4 \\
\hline Alagoas & 4,863 & 1,375 & 28.3 & 12,923 & 3,699 & 28.6 & 17,786 & 5,074 & 28.5 \\
\hline Bahia & 17,989 & 3,517 & 19.5 & 61,695 & 12,957 & 21.0 & 79,684 & 16,474 & 20.7 \\
\hline Ceará & 13,863 & 4,843 & 34.9 & 36,392 & 13,310 & 36.6 & 50,255 & 18,152 & 36.1 \\
\hline Maranhão & 6,567 & 2,914 & 44.4 & 25,801 & 9,196 & 35.6 & 32,367 & 12,111 & 37.4 \\
\hline Paraíba & 7,739 & 2,017 & 26.1 & 16,780 & 2,822 & 16.8 & 24,519 & 4,839 & 19.7 \\
\hline Pernambuco & 20,021 & 4,773 & 23.8 & 36,782 & 10,340 & 28.1 & 56,803 & 15,114 & 26.6 \\
\hline Piauí & 4,325 & 1,045 & 24.2 & 15,495 & 2,474 & 16.0 & 19,820 & 3,519 & 17.8 \\
\hline Rio Grande do Norte & 8,434 & 1,744 & 20.7 & 10,979 & 2,363 & 21.5 & 19,414 & 4,107 & 21.2 \\
\hline Sergipe & 3,471 & 930 & 26.8 & 8,640 & 2,143 & 24.8 & 12,111 & 3,073 & 25.4 \\
\hline South & 165,559 & 19,681 & 11.9 & 25,963 & 5,914 & 22.8 & 191,522 & 25,595 & 13.4 \\
\hline Paraná & 54,907 & 7,350 & 13.4 & 13,181 & 3,172 & 24.1 & 68,088 & 10,522 & 15.5 \\
\hline Rio Grande do Sul & 74,490 & 6,870 & 9.2 & 9,507 & 1,734 & 18.2 & 83,997 & 8,605 & 10.2 \\
\hline Santa Catarina & 36,162 & 5,461 & 15.1 & 3,275 & 1,008 & 30.8 & 39,438 & 6,469 & 16.4 \\
\hline Southeast & 360,159 & 55,837 & 15.5 & 201,052 & 52,381 & 26.1 & 561,212 & 108,218 & 19.3 \\
\hline Espírito Santo & 10,795 & 2,672 & 24.8 & 10,951 & 4,001 & 36.5 & 21,746 & 6,672 & 30.7 \\
\hline Minas Gerais & 67,317 & 11,269 & 16.7 & 62,374 & 11,347 & 18.2 & 129,691 & 22,616 & 17.4 \\
\hline Rio de Janeiro & 72,434 & 17,698 & 24.4 & 58,203 & 19,596 & 33.7 & 130,638 & 37,294 & 28.5 \\
\hline São Paulo & 209,613 & 24,198 & 11.5 & 69,524 & 17,438 & 25.1 & 279,136 & 41,636 & 14.9 \\
\hline Brazil & 664,618 & 117,037 & 17.6 & 551,678 & 153,284 & 27.8 & $1,216,296$ & 270,321 & 22.2 \\
\hline
\end{tabular}

twice as many excess deaths among the blacks $(25.1 \%, \mathrm{n}=17,438)$ than among whites $(11.5 \%, \mathrm{n}=24,198)$.

From 2015 to 2019, approximately $52 \%$ of the deaths by natural causes in the country happened among men (data not presented). The excess deaths observed in 2020 were also higher among men. Men reached a total of $25.2 \%(n=159,157)$ of excess deaths, while women reached $19.0 \%(n=111,164)$. For both sexes, the excess deaths were higher among the black population. The numbers of excess deaths were approximately $31.0 \%(n=93,200)$ for black men and $23.9 \%(n=60,084)$ for black women, while for white men and women, the excess was $20.0 \%(n=65,957)$ and $15.3 \%(n=51,080)$, respectively (Table $\mathbf{2}$ ).

The highest portion of deaths occurring in 2020 was concentrated in the age groups of $60-79$ years and 80 years and above. Excess deaths were higher for blacks than for whites in all age groups. In the younger age groups, Brazil had an excess of deaths among blacks of $32.9 \%(n=11,994)$ among those individuals younger than 29 years of age, and of $37.0 \%(n=46,996)$ in the age group of 30 to 
TABLE 2: Proportional excess mortality according to race/color and sex. Brazil, regions, and states, 2020.

\begin{tabular}{|c|c|c|c|c|}
\hline \multirow{2}{*}{ Location } & \multicolumn{2}{|c|}{ White } & \multicolumn{2}{|c|}{ Black } \\
\hline & Women & Men & Women & Men \\
\hline Midwest & 26.0 & 34.4 & 30.3 & 36.0 \\
\hline DF & 23.9 & 40.3 & 35.5 & 46.1 \\
\hline GO & 24.5 & 31.3 & 27.3 & 31.5 \\
\hline MS & 23.1 & 31.1 & 27.6 & 32.4 \\
\hline MT & 37.1 & 39.6 & 34.3 & 40.1 \\
\hline North & 44.3 & 50.4 & 33.5 & 40.9 \\
\hline$A C$ & 76.7 & 72.3 & 31.8 & 27.0 \\
\hline AM & 50.5 & 62.9 & 42.1 & 50.3 \\
\hline$A P$ & 50.1 & 65.0 & 44.8 & 51.5 \\
\hline PA & 41.3 & 47.9 & 28.3 & 38.2 \\
\hline RO & 34.1 & 36.4 & 34.6 & 37.1 \\
\hline $\mathrm{RR}$ & 53.7 & 79.2 & 63.1 & 60.6 \\
\hline TO & 43.7 & 42.7 & 29.0 & 33.2 \\
\hline Northeast & 23.4 & 30.2 & 21.8 & 30.2 \\
\hline $\mathrm{AL}$ & 23.3 & 34.3 & 22.4 & 34.4 \\
\hline BA & 17.2 & 22.2 & 18.5 & 23.2 \\
\hline CE & 32.5 & 37.8 & 28.5 & 43.8 \\
\hline MA & 39.5 & 49.1 & 29.9 & 39.9 \\
\hline PB & 22.3 & 30.7 & 13.9 & 19.4 \\
\hline PE & 19.9 & 28.7 & 22.7 & 33.0 \\
\hline $\mathrm{PI}$ & 21.9 & 26.7 & 14.6 & 17.1 \\
\hline $\mathrm{RN}$ & 19.0 & 22.5 & 19.3 & 23.4 \\
\hline SE & 26.2 & 27.4 & 20.8 & 28.2 \\
\hline South & 9.7 & 14.0 & 21.9 & 23.5 \\
\hline PR & 10.9 & 15.6 & 21.4 & 26.1 \\
\hline RS & 7.8 & 10.6 & 19.0 & 17.6 \\
\hline SC & 11.9 & 18.0 & 32.6 & 29.2 \\
\hline Southeast & 13.4 & 17.7 & 22.8 & 28.9 \\
\hline ES & 23.8 & 25.7 & 28.0 & 43.6 \\
\hline MG & 15.9 & 17.6 & 17.1 & 19.1 \\
\hline RJ & 18.4 & 31.3 & 26.5 & 40.8 \\
\hline $\mathrm{SP}$ & 10.2 & 12.9 & 23.8 & 26.1 \\
\hline Brazil & 15.3 & 20.0 & 23.9 & 31.0 \\
\hline
\end{tabular}

59 years, as compared to $22.6 \%(n=5,757)$ and $31.1 \%(n=29,701)$ of excess deaths in the white population, for the same age groups, respectively (Table $\mathbf{3}$ ).

When comparing the excess mortality between categories of race/color according to sex and age in the country, the highest difference was among elderly men, with almost twice as much excess deaths among blacks, at $19.7 \%(\mathrm{n}=14,990)$, as compared to $10.2 \%(\mathrm{n}=11,724)$ among whites (Figure 2). According to region, the excess mortality of young males also stands out in the South and Southeast regions, with a 2.6-fold higher proportion for blacks.

\section{DISCUSSION}

The present study reveals important racial disparities in excess mortality during the COVID-19 pandemic in Brazil, with a heterogeneous impact among states, sexes, and ages. The total excess mortality was 270,000 deaths, and the excess was 1.6-fold higher among blacks when compared to whites. Among elderly men, blacks had almost twice as many deaths as whites. The state of São Paulo stood out for its high disparity between blacks and whites, $25.1 \%$ and $11.5 \%$ (ratio of 2.17), respectively. Other studies have also shown that the impacts of mortality by COVID-19 are unequal among populations, especially in terms of socioeconomic and sociodemographic conditions ${ }^{18,19}$.

Excess deaths allow us to quantify the general impact of the COVID-19 pandemic in national mortality, regardless of cause of death. This indicator considers not only the deaths which reported COVID-19 as the declared cause, but also the deaths by COVID-19 which were not diagnosed and the deaths by other causes that can be attributed to the conditions caused by the crisis generated by the pandemic ${ }^{20}$. The comparative analysis at disaggregated levels, considering regionalized, demographic information, enables the identification of the most affected populations and, together with other relevant sources of data, can be used to aid in directing actions to control and prevent the disease in the country.

The distribution of the Brazilian population by race/color differs from region to region and according to state. In general, more than half of the Brazilian population is black (56\% in 2019). This percentage varies from $26 \%$ in the South to $79.5 \%$ in the North of the country. In terms of the age structure, the white population is older than the black, and far more numerous for individuals of 80 years of age and older ${ }^{16,17}$. In this study, however, when the excess mortality according to race/color in Brazil was analyzed, a higher excess among the black was found in all of the studied age groups. The highest differentials of excess death between the categories of race/color were in the extreme age groups, children and young adults ( $<29$ years) and the elderly (80 years and over) ${ }^{21}$.

The higher excess mortality in the white population in the North region of the country was unexpected, but could eventually be attributed to behavioral factors that are characteristic of that population group. It is important to bear in mind that the population on these states is mostly composed of what we are here denominating blacks, but in truth are a mix of Indians and other color/races. In general, the white population is a minority with a much higher income, more conditions to travel (international trips, for instance), and their COVID cases with more access to the small number of hospitals available in the region with higher probability of being notified to the $\mathrm{CR}$ registry.

It is important to mention that the states that have mainly white populations had a smaller proportion of excess deaths (Rio Grande do Sul, São Paulo, Paraná, and Santa Catarina). However, the excess mortality was much greater among the black population in those states and was more than double in São Paulo. If on the one hand 
we can attribute the lower percentages of excess mortality to better access to prevention and medical care in those states, on the other hand, the inequalities according to race/color are evident, with a far higher risk of death among blacks. The wide and complex racist effect involves three dimensions: personal - feelings and behavior, including inferiority/superiority and acceptance/refusal; interpersonal - actions and omissions manifested in the lack of respect, persecution, devaluing, and negligence when dealing with racism and its impacts; and institutional - reduced access to quality services, less access to information, and scarcity of resources and social control ${ }^{22}$. It is important for the racial differences to be highlighted so that societies can face this problem and can intervene in the factors which compromise the access to and use of health services in more egalitarian terms.

The higher excess mortality identified for blacks suggests an intrinsic relationship between race/color and lower socioeconomic status, vastly observed in other studies. In New York, the

TABLE 3: Proportional excess mortality according to race and age groups. Brazil, regions, and states, 2020.

\begin{tabular}{|c|c|c|c|c|c|c|c|c|}
\hline \multirow{2}{*}{ Location } & \multicolumn{4}{|c|}{ White } & \multicolumn{4}{|c|}{ Black } \\
\hline & 0 to 29 & 30 to 59 & 60 to 79 & $80+$ & 0 to 29 & 30 to 59 & 60 to 79 & $80+$ \\
\hline Midwest & 37.1 & 50.5 & 35.2 & 16.9 & 49.3 & 41.4 & 34.3 & 21.4 \\
\hline Federal District & 41.0 & 46.9 & 38.6 & 18.7 & 59.6 & 51.0 & 39.3 & 28.7 \\
\hline Goiás & 22.0 & 49.4 & 35.3 & 14.2 & 32.8 & 35.7 & 33.4 & 18.3 \\
\hline Mato Grosso do Sul & 61.5 & 39.7 & 28.7 & 16.3 & 88.6 & 45.6 & 24.5 & 17.0 \\
\hline Mato Grosso & 39.7 & 68.2 & 39.1 & 23.4 & 46.1 & 41.7 & 40.5 & 26.6 \\
\hline North & 41.5 & 70.6 & 55.9 & 31.1 & 20.4 & 39.9 & 46.2 & 32.0 \\
\hline Acre & 79.0 & 115.5 & 67.5 & 61.0 & 33.3 & 35.5 & 32.3 & 17.3 \\
\hline Amazonas & 23.7 & 75.9 & 73.0 & 42.1 & 14.7 & 49.4 & 58.5 & 45.7 \\
\hline Amapá & 54.9 & 85.7 & 58.8 & 41.8 & 16.7 & 58.0 & 58.6 & 46.3 \\
\hline Pará & 34.6 & 63.0 & 58.2 & 27.4 & 15.9 & 32.5 & 44.2 & 29.3 \\
\hline Roraima & 58.2 & 67.3 & 33.7 & 19.3 & 49.3 & 50.3 & 34.5 & 21.5 \\
\hline Rondônia & 69.3 & 98.8 & 67.7 & 49.4 & 59.0 & 65.4 & 61.7 & 58.1 \\
\hline Tocantins & 58.8 & 63.0 & 51.1 & 29.1 & 31.5 & 32.3 & 37.4 & 24.2 \\
\hline Northeast & 35.4 & 43.5 & 33.5 & 16.2 & 31.7 & 35.5 & 28.8 & 16.4 \\
\hline Alagoas & 34.2 & 40.7 & 38.0 & 14.6 & 43.8 & 39.5 & 29.1 & 15.8 \\
\hline Bahia & 20.6 & 34.3 & 25.5 & 12.1 & 12.8 & 31.4 & 24.9 & 11.6 \\
\hline Ceará & 27.0 & 50.5 & 45.2 & 25.9 & 54.6 & 43.8 & 42.0 & 24.9 \\
\hline Maranhão & 32.5 & 61.4 & 54.6 & 31.5 & 22.7 & 35.5 & 43.5 & 31.2 \\
\hline Paraíba & 47.9 & 47.8 & 29.3 & 16.7 & 32.6 & 28.6 & 16.3 & 8.5 \\
\hline Pernambuco & 56.6 & 41.7 & 31.1 & 10.3 & 65.6 & 44.1 & 25.7 & 13.0 \\
\hline Piauí & 45.1 & 37.2 & 26.8 & 16.5 & 16.1 & 21.8 & 19.0 & 9.4 \\
\hline Rio Grande do Norte & 26.8 & 36.9 & 25.7 & 12.1 & 24.0 & 31.1 & 19.3 & 17.2 \\
\hline Sergipe & 29.2 & 50.8 & 32.0 & 15.3 & 21.0 & 31.9 & 29.6 & 14.6 \\
\hline South & 19.1 & 22.5 & 13.8 & 4.9 & 53.2 & 34.4 & 19.8 & 12.7 \\
\hline Paraná & 23.2 & 24.9 & 15.6 & 4.9 & 58.3 & 37.7 & 22.1 & 11.0 \\
\hline Rio Grande do Sul & 14.6 & 19.1 & 10.9 & 3.7 & 49.2 & 26.3 & 14.9 & 12.3 \\
\hline Santa Catarina & 19.2 & 24.5 & 17.2 & 7.8 & 48.2 & 43.2 & 25.8 & 21.6 \\
\hline Southeast & 15.1 & 28.7 & 20.2 & 6.9 & 36.5 & 37.2 & 27.5 & 12.3 \\
\hline Espírito Santo & 36.9 & 44.8 & 31.1 & 12.8 & 55.0 & 52.2 & 36.5 & 18.8 \\
\hline Minas Gerais & 19.2 & 25.8 & 20.7 & 10.3 & 22.1 & 26.3 & 20.8 & 8.7 \\
\hline Rio de Janeiro & 42.7 & 44.7 & 31.0 & 11.7 & 62.1 & 49.7 & 32.5 & 16.1 \\
\hline São Paulo & 5.7 & 24.0 & 15.7 & 3.7 & 21.9 & 34.4 & 27.5 & 11.9 \\
\hline Brazil & 22.6 & 31.1 & 21.6 & 8.9 & 32.9 & 37.0 & 29.9 & 16.6 \\
\hline
\end{tabular}




\begin{tabular}{|c|c|c|c|c|c|c|c|c|}
\hline \multirow{2}{*}{\multicolumn{3}{|c|}{ Location, sex and age }} & \multicolumn{3}{|c|}{ White } & \multicolumn{3}{|c|}{ Black } \\
\hline & & & \multirow{2}{*}{$\begin{array}{c}\text { Expected } \\
11,360\end{array}$} & \multirow{2}{*}{$\begin{array}{c}\text { Excess } \\
2,333\end{array}$} & \multirow{2}{*}{$\begin{array}{c}\% \\
20.5\end{array}$} & \multirow{2}{*}{$\begin{array}{c}\text { Expected } \\
14,976\end{array}$} & \multirow{2}{*}{$\begin{array}{c}\text { Excess } \\
3,963\end{array}$} & \multirow{2}{*}{$\begin{array}{c}\% \\
26.5\end{array}$} \\
\hline \multirow{8}{*}{ Brazil } & \multirow{4}{*}{ Women } & 0 to 29 & & & & & & \\
\hline & & 30 to 59 & 40,850 & 11,539 & 28.2 & 50,454 & 16,680 & 33.1 \\
\hline & & 60 to 79 & 116,556 & 24,017 & 20.6 & 96,609 & 26,903 & 27.8 \\
\hline & & $80+$ & 165,653 & 13,191 & 8.0 & 89,232 & 12,538 & 14.1 \\
\hline & \multirow{4}{*}{ Men } & 0 to 29 & 14,077 & 3,424 & 24.3 & 21,517 & 8,031 & 37.3 \\
\hline & & 30 to 59 & 54,585 & 18,163 & 33.3 & 76,395 & 30,316 & 39.7 \\
\hline & & 60 to 79 & 146,241 & 32,646 & 22.3 & 126,340 & 39,864 & 31.6 \\
\hline & & $80+$ & 115,296 & 11,724 & 10.2 & 76,155 & 14,990 & 19.7 \\
\hline \multirow{8}{*}{ Midwest } & \multirow{4}{*}{ Women } & 0 to 29 & 839 & 315 & 37.6 & 1,141 & 464 & 40.7 \\
\hline & & 30 to 59 & 2,397 & 1,040 & 43.4 & 4,040 & 1,507 & 37.3 \\
\hline & & 60 to 79 & 6,305 & 2,029 & 32.2 & 7,237 & 2,398 & 33.1 \\
\hline & & $80+$ & 7,889 & 1,147 & 14.5 & 5,611 & 1,087 & 19.4 \\
\hline & \multirow{4}{*}{ Men } & 0 to 29 & 1,128 & 415 & 36.7 & 1,535 & 855 & 55.7 \\
\hline & & 30 to 59 & 3,037 & 1,702 & 56.0 & 6,462 & 2,838 & 43.9 \\
\hline & & 60 to 79 & 7,773 & 2,929 & 37.7 & 10,244 & 3,606 & 35.2 \\
\hline & & $80+$ & 6,425 & 1,270 & 19.8 & 5,871 & 1,371 & 23.3 \\
\hline \multirow{8}{*}{ North } & \multirow{4}{*}{ Women } & 0 to 29 & 692 & 256 & 37.0 & 2,635 & 591 & 22.4 \\
\hline & & 30 to 59 & 1,153 & 762 & 66.1 & 5,213 & 1,920 & 36.8 \\
\hline & & 60 to 79 & 2,562 & 1,465 & 57.2 & 8,497 & 3,456 & 40.7 \\
\hline & & $80+$ & 3,305 & 936 & 28.3 & 7,582 & 2,048 & 27.0 \\
\hline & \multirow{4}{*}{ Men } & 0 to 29 & 794 & 361 & 45.4 & 4,158 & 792 & 19.0 \\
\hline & & 30 to 59 & 1,380 & 1,027 & 74.5 & 8,259 & 3,457 & 41.9 \\
\hline & & 60 to 79 & 3,223 & 1,769 & 54.9 & 12,829 & 6,400 & 49.9 \\
\hline & & $80+$ & 2,725 & 939 & 34.5 & 7,863 & 2,895 & 36.8 \\
\hline \multirow{8}{*}{ Northeast } & & 0 to 29 & 1,947 & 653 & 33.5 & 6,341 & 1,433 & 22.6 \\
\hline & & 30 to 59 & 5,298 & 2,154 & 40.6 & 19,167 & 5,872 & 30.6 \\
\hline & Women & 60 to 79 & 14,303 & 4,627 & 32.4 & 37,830 & 10,014 & 26.5 \\
\hline & & $80+$ & 25,389 & 3,553 & 14.0 & 40,529 & 5,315 & 13.1 \\
\hline & & 0 to 29 & 2,301 & 851 & 37.0 & 9,330 & 3,534 & 37.9 \\
\hline & Man & 30 to 59 & 6,061 & 2,784 & 45.9 & 29,480 & 11,389 & 38.6 \\
\hline & Men & 60 to 79 & 15,272 & 5,285 & 34.6 & 47,905 & 14,704 & 30.7 \\
\hline & & $80+$ & 16,702 & 3,249 & 19.5 & 34,907 & 7,044 & 20.2 \\
\hline & & 0 to 29 & 2,549 & 365 & 14.3 & 447 & 187 & 41.8 \\
\hline & & 30 to 59 & 10,594 & 1,955 & 18.5 & 2,532 & 851 & 33.6 \\
\hline & women & 60 to 79 & 29,781 & 3,837 & 12.9 & 4,973 & 1,075 & 21.6 \\
\hline & & $80+$ & 37,437 & 1,632 & 4.4 & 3,712 & 440 & 11.8 \\
\hline South & & 0 to 29 & 3,214 & 734 & 22.8 & 617 & 379 & 61.4 \\
\hline & Man & 30 to 59 & 14,992 & 3,789 & 25.3 & 3,739 & 1,309 & 35.0 \\
\hline & Men & 60 to 79 & 40,238 & 5,836 & 14.5 & 6,654 & 1,226 & 18.4 \\
\hline & & $80+$ & 26,756 & 1,533 & 5.7 & 3,288 & 447 & 13.6 \\
\hline & & 0 to 29 & 5,334 & 743 & 13.9 & 4,412 & 1,288 & 29.2 \\
\hline & Womon & 30 to 59 & 21,408 & 5,629 & 26.3 & 19,502 & 6,531 & 33.5 \\
\hline & Women & 60 to 79 & 63,605 & 12,059 & 19.0 & 38,073 & 9,960 & 26.2 \\
\hline Southeast & & $80+$ & 91,633 & 5,923 & 6.5 & 31,799 & 3,648 & 11.5 \\
\hline Southeast & & 0 to 29 & 6,640 & 1,064 & 16.0 & 5,877 & 2,471 & 42.0 \\
\hline & & 30 to 59 & 29,115 & 8,859 & 30.4 & 28,455 & 11,323 & 39.8 \\
\hline & Men & 60 to 79 & 79,735 & 16,828 & 21.1 & 48,709 & 13,927 & 28.6 \\
\hline & & $80+$ & 62,688 & 4,732 & 7.5 & 24,226 & 3,234 & 13.3 \\
\hline Proportional & ss mortality: & $4 \%[$ & & $74.4 \%$ & & & & \\
\hline
\end{tabular}


numbers of admissions to hospitals and of in-hospital deaths from COVID-19 were higher in neighborhoods with a higher proportion of racial/ethnic minorities, in families living in poverty, and those individuals with a lower level of education ${ }^{23}$. Higher rates of mortality were also observed in counties with a higher percentage of people who identified themselves as African-American (IRR, 1.02; 95\% CI, 1.02-1.03; $\mathrm{P}<0.001)$ and other racial/ethnic minorities ${ }^{24}$. In the city of São Paulo, Ribeiro et al. ${ }^{19}$ observed a higher rate of mortality among blacks, which was 1.77 -fold higher than in whites, and verified a gradient of this disparity as the socioeconomic indicators became worse, especially for people under 60 years of age. Moreover, in Brazil, Baqui et al. ${ }^{25}$ not only noticed a higher risk of death in hospitals for blacks in comparison to whites, but also the category "colored" was the second most important death risk after increasing age.

In Brazil, $70 \%$ of people below the poverty line (internationally defined by the World Bank as US\$ 1.90 per day) are black or biracial, although $56.3 \%$ of the total population declare themselves as being of that race/color ${ }^{26}$. This finding makes people more likely to live in overcrowded conditions, in multi-generational families, which makes it harder to maintain social distancing ${ }^{27}$. The higher inadequacy of homes found among blacks, including sanitation problems, also determines a higher difficulty to apply adequate prevention habits, like proper hand hygiene ${ }^{26}$.

Another factor to be considered is that this population often works in informal jobs ${ }^{26}$; they depend on jobs which cannot be done remotely ${ }^{27}$. Even the people who can stay at home most likely live with someone who is an essential worker; therefore, they are more likely to be exposed to infection by SARS-CoV- $2^{28,29}$. Moreover, they are more likely to use (and for longer distances) public transportation, which also exposes them to a higher risk of contamination ${ }^{27}$.

The fact that this population has less education might make it more difficult for them to understand messages about prevention, symptoms, and ways of disseminating COVID-1924. Adding this to the other problems, the black population shows a higher prevalence of chronic comorbidities, such as hypertension ${ }^{30}$, diabetes ${ }^{31}$, and obesity $^{32}$, all risk factors that can result in worse outcomes for COVID-1924. The greater difficulty in access to health services ${ }^{33}$ also contributes to having more serious complications of COVID-19, as they seek out medical care too late.

This study has some limitations, as it used two systems as a data source. It is well-known that the data from SIM undergoes a rigorous quality control process at all levels. This makes data more reliable, but it also makes it harder to develop studies capable of providing fast feedback in the course of a pandemic, since it takes nearly two years for SIM data to become available. Therefore, even considering that two sources of data were used, the analysis of the excess death estimates conducted in the present study were considered opportune and helped call attention to the racial disparities in the country.

Another limitation that should be highlighted is related to the methodology for the correction of the missing data on color/race, an essential step in creating the correction factors of the underreporting of the CR. Even though methods were applied to treat data at the state level, taking into consideration local characteristics, the quality of the generated information is unequal among the states ${ }^{15}$. For the redistribution of the missing data, we followed the premise that the data missing from the $\mathrm{CR}$ was equal to that of the registries filled out by the SIM for Brazil; values were differentiated when different strata were considered, especially concerning small numbers. It should also be emphasized that this redistribution took into consideration the state, sex, and age groups to contemplate the local differences.

Even though life is a fundamental right guaranteed by law in Brazil, with no distinction of any kind, the universal and integral guarantee of health services as an obligation of the State (with no prejudice regarding origin, race, sex, age, or any other form of prejudice) is a different reality. Disparities in mortality according to race /color are evidence of the structural inequalities which exist in Brazil; access to health is divergent and, consequently, the right to life is unequal. Considering the disparity in mortality related to the COVID-19 pandemic, the present study helped to expose the Brazilian reality even further, a reality in which "the color of the skin is a marker of difference" ${ }^{34}$.

\section{FINANCIAL SUPPORT}

This research was supported by Vital Strategies, as part of the Bloomberg Philanthropies Data for Health Initiative.

\section{AUTHORS' CONTRIBUTION}

RAT, AMNV, AT, FM: conception of the study; RAT: extraction, management and analysis of data; RAT, AMNV, AT, FM, ALB, EBF, DMXA, LI: interpretation of data and manuscript writing; RAT, AMNV, AT, FM, ALB, EBF, DMXA, LI: data interpretation and critical revision of the manuscript. All of the authors approved the final text.

\section{CONFLICT OF INTEREST}

The authors declare that they have no conflict of interests.

\section{ORCID}

Renato Azeredo Teixeira: 0000-0002-1259-6812

Ana Maria Nogales Vasconcelos: 0000-0001-7589-107X

Ana Torens: 0000-0002-5955-971X

Elisabeth Barboza França: 0000-0001-6984-0233

Lenice Ishitani: 0000-0002-7165-4736

Ana Luiza Bierrenbach: 0000-0002-6837-0636

Daisy Maria Xavier de Abreu: 0000-0002-6855-8612

Fátima Marinho: 0000-0003-3287-9163

\section{REFERENCES}

1. https://www.who.int/dg/speeches/detail/who-director-general-sstatement-on-ihremergency-committee-on-novel-coronavirus-(2019ncov) WHOWD-G statement on IEC on NC (2019-nCoV). HE of IC declared. 2020. 
2. Brasil. Ministério da Saúde. Portaria n 188 de 3 de fevereiro de 2020. DO da U [Internet]. B 2020. https://bvsms.saude.gov.br/bvs/saudelegis/ gm/2020/prt0188_04_02_2020.html.

3. Ministério da Saúde. Coronavírus Brasil. Avaliable from: https://covid. saude.gov.br/.

4. Johns Hopkins University and Medicine. COVID-19 Dashboard by the Center for Systems Science and Engineering (CSSE) at Johns Hopkins University (JHU). Available from: https://coronavirus.jhu.edu/map. html. 2022.

5. Secretaria de Estado da Saúde de São Paulo. Resolução SS No 32 - 20 de Março de 2020.

6. França EB, Ishitani LH, Teixeira RA, Abreu DMX, Corrêa PRL, Marinho F, et al. Deaths due to covid-19 in Brazil: How many are there and which are being identified? Rev Bras Epidemiol. 2020;23:1-7.

7. Vital Strategies. Revealing the Toll of COVID-19: A Technical Package for Rapid Mortality Surveillance and Epidemic Response. 2020;(May). Available from: https://www.who.int/publications/i/item/revealing-thetoll-of-covid-19

8. Orellana JDY, Cunha GM, Marrero L, Moreira RI, Leite IC, Horta BL. Excess deaths during the COVID-19 pandemic: underreporting and regional inequalities in Brazil. Cad Saúde Pública. 2021:37(1):e00259120. Available from: https://doi.org/10.1590/0102-311x00259120 9.

9. Araújo EM, Costa MCN, Hogan VK, Mota ELA, Araújo TM, Oliveira, NF. Race/skin color differentials in potential years of life lost due to external causes. Rev Saúde Pública. 2009;43(3):405-12. Available from: https://doi.org/10.1590/S0034-89102009005000021.

10. Santos MPA, Nery JS, Goes EF, da Silva A, dos Santos ABS, Batista LE, et al. População negra e Covid-19: Reflexões sobre racismo e saúde. Estudos Avançados. 2020;34(99):225-44.

11. Ministério da Saúde. Sistema de Informação sobre Mortalidade (SIM) [Internet]. 2022. Available from: http://svs.aids.gov.br/dantps/cgiae/sim/.

12. Ministério da Saúde. Informações de Saúde (Tabnet). 2022. Available from: http://www2.datasus.gov.br/DATASUS/index.php?area=02.

13. Associação Nacional dos Registros de Pessoas Naturais (ARPEN). Portal da Transparência. Especial COVID-19. 2022. Aviliable from: https://transparencia.registrocivil.org.br/especial-covid.

14. Brasil. Ministério da Saúde. Secretaria de Vigilância em Saúde. Departamento de Análise de Situação de Saúde. Manual de Instruções para o preenchimento da Declaração de Óbito. Ministério da Saúde, Secretaria de Vigilância em Saúde, Departamento de Análise. 2001.

15. Costa LFL, Montenegro MMS, Rabello Neto DDL, Oliveira ATR, Trindade JEDO, Adair T, Marinho MF. Estimating completeness of national and subnational death reporting in Brazil: Application of record linkage methods. Popul Health Metrics. 2020;18:22. Available from: https://doi.org/10.1186/s12963-020-00223-2

16. Instituto Brasileiro de Geografia e Estatísticas (IBGE). Pesquisa Nacional por Amostra de Domicílios Contínua (PNAD). Rio de Janeiro: IBGE; 2020.

17. IBGE. Projeções da População - Brasil e Unidades da Federação. IBGE. 2018;41:1-81.

18. Golestaneh L, Neugarten J, Fisher M, Billett HH, Gil MR, Johns T, et al. The association of race and COVID-19 mortality. EClinicalMedicine. 2020;25:100455. Available from: https://doi.org/10.1016/j. eclinm.2020.100455.

19. Ribeiro KB, Ribeiro AF, Veras MACM, Castro MC. Social inequalities and COVID-19 mortality in the city of São Paulo, Brazil. Int J Epidemiol. 2021;50(3):732-42. Available from: https://doi.org/10.1093/ije/dyab022.
20. Checchi F, Roberts L. Interpreting and using mortality data in humanitarian emergencies. Humanitarian Practice Network. 2005;52:141. Available from: https://odihpn.org/resouCRes/interpreting-andusing-mortality-data-in-humanitarian-emergencies/

21. Marinho MF, Teixeira R, Machado HA, Lima M, Venturini AC, Sousa $\mathrm{CJ}$, et al. Disparidades raciais no excesso de mortalidade em tempos de Covid-19 em São Paulo. Informativos Desigualdades Raciais e Covid19, AFRO-CEBRAP, n. 8, 2021.

22. Werneck J. Institutional racism and black population health. Saude Soc. 2016;25(3):535-49. Available from: https://doi.org/10.1590/s0104129020162610.535 .

23. Wadhera RK, Wadhera P, Gaba P, Figueroa JF, Joynt Maddox KE, Yeh RW, et al. Variation in COVID-19 Hospitalizations and Deaths Across New York City Boroughs. JAMA. 2020;323(21):2192-5. Available from: https://doi.org/10.1001/jama.2020.7197

24. Karmakar M, Lantz PM, Tipirneni R. Association of Social and Demographic Factors With COVID-19 Incidence and Death Rates in the US. JAMA Netw Open. 2021;4(1):e2036462. Available from: https:// doi.org/10.1001/jamanetworkopen.2020.36462

25. Baqui P, Bica I, Marra V, ECRole A, van der Schaar M. Ethnic and regional variations in hospital mortality from COVID-19 in Brazil: a cross-sectional observational study. Lancet Glob Heal. 2020;8(8):e101826. Available from: https://doi.org/10.1016/S2214-109X(20)30285-0

26. IBGE, Coordenação de População e Indicadores Sociais. Síntese de indicadores sociais : uma análise das condições de vida da população brasileira : 2020. - Rio de Janeiro: IBGE, 2020. 148 p. (Estudos e Pesquisas. Informação Demográfica e Socioeconômica).

27. Oliveira RG, Cunha AP, Gadelha AGS, Carpio CG, Oliveira RB, Corrêa RM. Racial inequalities and death on the horizon: COVID-19 and structural racism. Cad Saúde Pública. 2020;36(9):e00150120. Available from: https://doi.org/10.1590/0102-311x00150120

28. Lopez L, Hart LH, Katz MH. Racial and Ethnic Health Disparities Related to COVID-19. JAMA. 2021;325(8):719-20. Available from: https://doi.org/10.1001/jama.2020.26443

29. McCormack G, Avery C, Spitzer AKL, Chandra A. Economic Vulnerability of Households with Essential Workers. JAMA. 2020;324(4):388-90. Available from: https://doi.org/10.1001/ jama.2020.11366

30. Malta DC, Bernal RTI, Andrade SSCA, Silva MMAD, VelasquezMelendez G. Prevalence of and factors associated with selfreported high blood pressure in Brazilian adults. Rev Saúde Publica. 2017;51(suppl 1):11s. Available from: https://doi.org/10.1590/s15188787.2017051000006 PMID: 28591346; PMCID: PMC5676350.31.

31. Malta DC, Duncan BB, Schmidt MI, Machado IE, Silva AG, Bernal RTI, et al. Prevalência de diabetes mellitus determinada pela hemoglobina glicada na população adulta brasileira, Pesquisa Nacional de Saúde. Rev Bras Epidemiol. 2019;22(Suppl. 2):E190006.SUPL.2. Available from: https://doi.org/10.1590/1980-549720190006.supl.2

32. Oraka CS, Faustino DM, Oliveira E, Teixeira JAM, Souza, ASP, Luiz OC. Race and obesity in the black female population: a scoping review. Saúde Soc. 2020;29(3):e191003. Available from: https://doi.org/10.1590/ S0104-12902020191003

33. Pereira RHM, Braga CKV, Serra B, Nadalin VG. Desigualdades socioespaciais de acesso a oportunidades nas cidades brasileiras 2019. Texto para discussão / Instituto de Pesquisa Econômica Aplicada - Brasília : Rio de Janeiro : Ipea, 2020. http://repositorio.ipea.gov.br/ bitstream/11058/9586/1/td_2535.pdf

34. Schwacrz LM, Starling HM. Brasil: uma biografia. São Paulo, Companhia das Letras, 2015. p.92. 